\title{
Left ventricular thrombosis and cerebrovascular accident in acute myocardial infarction
}

\author{
KARL-ARNE JOHANNESSEN, JAN ERIK NORDREHAUG, GERHARD VON DER LIPPE \\ From the Medical Department, Diakonissehjemmets Sykehus, Bergen, Norway
}

SUMMARY In a prospective study of 90 consecutive patients with acute myocardial infarction, 15 (28.3\%) of 53 patients with an anterior wall infarction developed a left ventricular thrombosis diagnosed by cross sectional echocardiography. Patients received anticoagulants only after a left ventricular thrombosis had been diagnosed. Twenty eight patients had an inferior infarction, but none of these had a left ventricular thrombosis. Five (5.5\%) of the 90 patients suffered a cerebrovascular accident, and all had an anterior wall infarction. In four of these five patients a left ventricular thrombosis was confirmed by echocardiography before the cerebrovascular accident. All patients with left ventricular thrombosis had apical akinesis. The incidence of a thrombosis did not differ in patients with a first anterior myocardial infarction and with reinfarctions. Among the 40 patients with a first anterior wall infarction, 12 with a thrombosis had a significantly higher incidence of enlarged heart on chest radiographs and significantly higher serum aspartate aminotransferase enzyme activity than those without.

Thus patients with a large anterior wall infarction and with akinesis in the apical region are at high risk of developing a left ventricular thrombosis, which may be a source of peripheral emboli. Left ventricular thrombosis appears to be rare with infarctions in other locations.

Cross sectional echocardiography is a reliable method for detecting left ventricular thrombosis. ${ }^{1-3}$ Several retrospective reports have suggested a high incidence of left ventricular thrombosis in patients who have had peripheral emboli after a myocardial infarction. ${ }^{145}$ In one prospective study, ${ }^{6}$ a high incidence of left ventricular thrombosis in acute anterior wall infarctions was found, but peripheral emboli were not diagnosed. The study was restricted to a subgroup of patients with a first myocardial infarction in whom its diagnosis was based on the presence of new $Q$ waves in an electrocardiogram. Furthermore, the patients were treated with heparin subcutaneously from their admission to hospital. Such treatment is not used routinely in many coronary care units at present.

In this prospective study of patients with acute myocardial infarction anticoagulants were given only when a left ventricular thrombus had been diagnosed. The objectives of the study were to determine $(a)$ the incidence of and predisposing factors for left ventricu-

Requests for reprints to Dr Karl-Arne Johannessen, Diakonissehjemmets Sykehus, Ulriksdal 8c, 5000 Bergen, Norway.

Accepted for publication 1 December 1983 lar thrombosis and (b) the incidence of possible peripheral emboli.

\section{Patients and methods}

During a six month period 90 consecutive patients of all ages admitted to our coronary care unit with confirmed acute myocardial infarction were studied. The criteria for diagnosis have been described in detail elsewhere ${ }^{7}$ and consisted of at least two of the following: (a) clinical symptoms-central chest pain for more than 30 minutes, acute cardiogenic shock, or pulmonary oedema; (b) electrocardiographic changes-development of new $Q$ waves or ST-T changes, or both, diagnostic for acute myocardial infarction; and (c) laboratory findings-transient increase in peak aspartate aminotransferase enzyme activity to more than twice the upper limit of normal of 40 units/l.

All patients were admitted to the unit and were treated with tranquillising agents, analgesics, and oxygen in the acute phase. They gradually became ambulant after the first day of admission. Anticoagulants were given only after a left ventricular thrombosis had been diagnosed. Oral treatment with warfa- 
rin was then started, and a thrombotest level between $5 \%$ and $10 \%$ was regarded as the therapeutic level. ${ }^{8}$ Treatment with salicylates and other platelet inhibiting agents was not given. A standard 12 lead electrocardiogram was recorded on admission to the unit, on the following day, and on later occasions when it was necessary for follow up.

A cerebrovascular accident was defined as the occurrence of transient or persisting paresis or paralysis in the extremities or face or both. Dizziness or syncope alone were not accepted as diagnostic criteria. No attempt was made to differentiate clinically between cerebral haemorrhage, embolism, or thrombosis.

\section{ECHOCARDIOGRAPHY}

Cross sectional echocardiography was performed with a Toshiba SSH-10 phased array sector scanner. All patients were examined on day 5 and day 10 after the infarction. When a thrombus was diagnosed several scans were recorded at varying intervals during follow up. We used parasternal and apical views with a systematic approach for left ventricular thrombosis. The criteria for diagnosing an intraventricular mass as a left ventricular thrombosis were $(a)$ a definite margin of an intraventricular mass towards the ventricular cavity in addition to at least one of the following: (b) a clear delineation of the endocardium at the site of the intraventricular mass; $(c)$ independent movement of the intraventricular mass; or $(d)$ a variation in the size of the intraventricular mass during serial examinations. To minimise the risk of mistaking artefacts (side lobes, reverberations) and other intracavitary structures (for example papillary muscles, muscular trabeculae) for thrombi, the diagnosis of left ventricular thrombosis had to be confirmed in at least two planes at very different angles. The diagnosis of left ventricular thrombosis was made by at least two independent observers. Adequate echocardiographic data were obtained in all but two patients.

\section{STATISTICAL ANALYSIS}

For statistical analysis we used the two tail $t$ test and Fisher's exact test; $p<0.05$ was regarded as statistically significant.

\section{Results}

Left ventricular thrombi were found in 15 (17\%) of the 90 patients. The cross sectional echocardiographic findings in patients with left ventricular thrombosis are shown in Table 1. All patients had akinesis of the apical region, where all the thrombi were located.

Table 2 shows the relation between thrombi, infarct site, and cerebrovascular accident. Only patients with anterior wall infarctions developed a left ventricular
Table 1 Cross sectional echocardiographic findings in 15 patients with a left ventricular thrombus

\begin{tabular}{ll}
\hline & No of patients \\
\hline $\begin{array}{l}\text { Definite thrombus margin } \\
\text { Clear delineation of endocardium at site } \\
\quad \text { of thrombus }\end{array}$ & 15 \\
$\begin{array}{l}\text { Resolution of thrombus during serial } \\
\text { examination }\end{array}$ & 15 \\
$\begin{array}{l}\text { Independent movement of thrombus } \\
\text { Apical akinesis }\end{array}$ & 14 \\
Recurrence of thrombus when & 6 \\
anticoagulation was stopped & 15 \\
\hline
\end{tabular}

Table 2 Number of patients with a left ventricular thrombus (LVT) and cerebrovascular accident (CVA) related to infarct location

\begin{tabular}{llll}
\hline $\begin{array}{lll}\text { Infarct } \\
\text { location }\end{array}$ & $\begin{array}{l}\text { Total No of } \\
\text { patients }\end{array}$ & $\begin{array}{l}\text { No (\%) with } \\
\text { LVT }\end{array}$ & $\begin{array}{l}\text { No (\%) with } \\
C V A\end{array}$ \\
\hline Anterior & 53 & $15(28 \%)$ & $5(9.4 \%)$ \\
Inferior & 28 & 0 & 0 \\
Uncertain & 9 & 0 & 0 \\
Total & 90 & $15(17 \%)$ & $5(5.5 \%)$ \\
\hline
\end{tabular}

Table 3 Number of patients with a left ventricular thrombus $(L V T)$ in frust anterior myocardial infarctions and reinfarctions

\begin{tabular}{lll}
\hline & No of patients & No (\%) with LVT \\
\hline Initial infarction & 40 & $12(30 \%)$ \\
Reinfarction & 13 & $3(23 \%)$ \\
Total & 53 & $15(28 \%)$ \\
\hline
\end{tabular}

Table 4 Clinical fondings in patients with furst anterior wall infarctions with and without a left ventricular thrombus (LVT)

\begin{tabular}{lll}
\hline Characteristic & $\begin{array}{l}L V T \\
(n=12)^{\star}\end{array}$ & $\begin{array}{l}\text { No LVT } \\
(n=28)^{\star}\end{array}$ \\
\hline $\begin{array}{l}\text { Mean ( } \pm \text { SD) age (yr) } \\
\begin{array}{l}\text { No of patients with: } \\
\text { Heart failure in first three days }\end{array}\end{array}$ & $63 \cdot 2 \pm 7.8$ & $58.6 \pm 11 \cdot 1$ \\
$\begin{array}{l}\text { Hypotension (systolic pressure } \\
\quad<100 \text { mmHg) in first three days }\end{array}$ & 2 & 8 \\
$\begin{array}{l}\text { Temperature }>38^{\circ} \mathrm{C} \text { in first } \\
\text { five days (mean } \pm \text { SD days) }\end{array}$ & $2.67 \pm 1.8$ & $2 \cdot 33 \pm 2.1$ \\
\hline
\end{tabular}

^Differences not significant.

Table 5 Laboratory data in patients with forst anterior wall infarctions with and without a left ventricular thrombus (LVT)

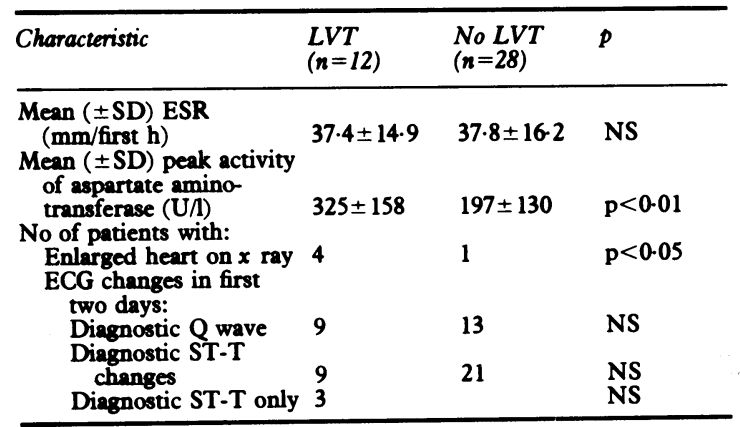

NS, not significant. 
thrombosis. A cerebrovascular accident was seen in five (5.5\%) of the 90 patients, all of whom had anterior wall infarctions. No patients had clinical signs of emboli in the extremities or abdominal circulation. One patient had a cerebrovascular accident on the fourth day after the acute myocardial infarction. At echocardiography on the fifth day no left ventricular thrombosis was found. The other four patients had a confirmed left ventricular thrombosis when a cerebrovascular accident occurred. One of these patients had had a cerebrovascular accident before optimal anticoagulation had been attained. He was left with a severe permanent hemiplegia. The other three patients had a transient hemiparesis lasting from 12 hours to five days and were fully recovered on discharge from hospital. All three were optimally anticoagulated when the cerebrovascular accident occurred.

Serial examinations of the patients during the initial hospital admission showed that several thrombi developed a central clearing which progressed until only a thin shell of the thrombus remained (Figure). One of these patients had a cerebrovascular accident lasting for less than 12 hours. Cross sectional echocardiography 10 minutes after the cerebrovascular accident had occurred showed that the major part of the remnant of the thrombus had disappeared.

Table 3 shows the incidence of left ventricular thrombosis in patients with a first anterior myocardial infarction and with reinfarctions (history or electrocardiographic evidence of a previous myocardial infarction). There was no significant difference between these two groups.

A comparison of various clinical and laboratory indices in patients with a first anterior wall infarction with and without a left ventricular thrombosis showed a higher incidence of enlarged hearts on $x$-ray films and a higher mean peak activity of aspartate aminotransferase in the group with a left ventricular thrombosis (Tables 4 and 5).

\section{Discussion}

This study shows a high occurrence of left ventricular thrombosis in the apical region in an acute anterior myocardial infarction in patients who did not receive anticoagulants before a left ventricular thrombosis had been diagnosed. High peak aspartate aminotransferase activity, a radiologically enlarged heart, and left ventricular apical akinesis seemed to favour the development of a left ventricular thrombosis. Apical akinesis was also seen in $32 \%$ of patients with an anterior infarction without a left ventricular thrombosis. This group had significantly lower enzyme values of aspartate aminotransferase, suggesting that the extent of injured myocardium may have been less.
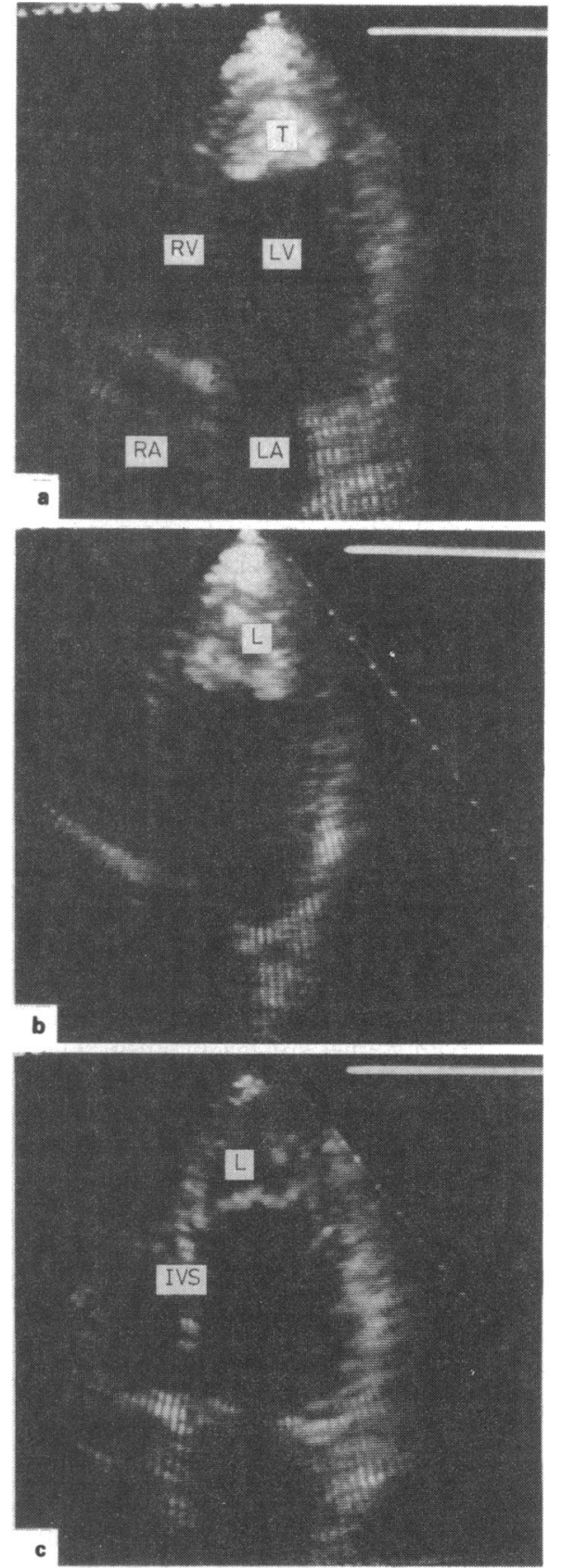

Figure Serial cross sectional echocardiograms in the four chamber view showing an apical thrombus developing central lysis. $T$, thrombus; $L$, lysis; $L V$, left ventricle; $L A$, left atrium; IVS, interventricular septum; $R V$, right ventricle, $R A$ right atrium. 
The patients in this study underwent routine echocardiography on days 5 and 10 after the acute infarction. A left ventricular thrombosis has been reported to occur on the first day after an infarction, ${ }^{6}$ and it is possible that such early thrombi may have lysed by day 5 and therefore have escaped detection. Nevertheless, none of the left ventricular thrombi that we did diagnose disappeared completely in such a short period. We therefore believe that the risk of our not having detected early lysed thrombi was probably small.

The results confirm and extend the findings of a previous prospective study of Asinger et al. ${ }^{6}$ In both studies, the thrombi were only found together with apical akinesis and were associated with large infarctions. Whereas Asinger et al restricted their study to first myocardial infarctions we found the same incidence of left ventricular thrombosis in patients with first anterior myocardial infarctions and with reinfarctions. The electrocardiographic criteria were different; in addition to the $Q$ wave changes used by Asinger $e t$ al we included patients with ST-T changes alone and found thrombi in three of these patients (Table 5). Clearly, therefore, the group of patients at high risk of developing left ventricular thrombosis was larger than that found by Asinger et al.

The most significant discrepancy in the two studies was the incidence of thromboembolic phenomena. Asinger et al did not detect this complication, whereas we found an incidence of $5.5 \%$ of the total group and of $27 \%$ in the group of patients with a left ventricular thrombosis. The reason for this discrepancy is unclear. In both studies anticoagulants in therapeutic doses (intravenous heparin or warfarin tablets or both) were not given before a left ventricular thrombosis had been diagnosed. On the other hand, the patients of Asinger $e t$ al were given prophylactic anticoagulation with low dose subcutaneous heparin on admission to the coronary care unit. Once a thrombus had been diagnosed, treatment with intravenous heparin and sodium warfarin tablets was given in the former study whereas only warfarin in therapeutic oral doses was given in our study. One possible explanation is therefore that when a thrombus is diagnosed intravenous anticoagulation treatment prevents embolism from that thrombus. Nevertheless, it remains to be seen whether anticoagulants in therapeutic doses on admission to hospital also prevent formation of a thrombus. The central clearing that we found in some thrombi was probably a central lysis, suggesting that the thrombi were decomposing from within.
Left ventricular thrombosis has been reported in patients with congestive cardiomyopathy with disturbed left ventricular function but no endothelial damage. ${ }^{5910}$ This finding, together with the predilection of thrombi for the apex rather than the inferior wall, makes it likely that the haemodynamic disturbances rather than the endothelial damage in acute myocardial infarction are mainly responsible for the development of ventricular thrombi.

We conclude that patients with large anterior wall infarctions with apical akinesis are at a high risk of developing left ventricular thrombosis, which may be a source of peripheral emboli. The appropriate treatment for this group of patients remains to be decided.

\section{References}

1 Stratton JR, Lighty GW Jr, Pearlman AS, Ritchie JL. Detection of left ventricular thrombus by twodimensional echocardiography: sensitivity, specificity, and causes of uncertainty. Circulation 1982; 66: 156-66.

2 Ezekowitz MD, Wilson DA, Smith EO, et al. Comparison of indium-lll platelet scintigraphy and twodimensional echocardiography in the diagnosis of left ventricular thrombi. $N$ Engl F Med 1982; 306: 1509-13.

3 Asinger RW, Mikell FL, Sharma B, Hodges M. Observations on detecting left ventricular thrombus with twodimensional echocardiography: emphasis on avoidance of false positive diagnoses. Am F Cardiol 1981; 47: 145-56.

4 DeMaria AN, Bommer W, Neumann A, et al. Left ventricular thrombi identified by cross-sectional echocardiography. Ann Intern Med 1979; 90: 14-8.

5 Stratton JR, Ritchie JL, Hamilton GW, Hammermeister $\mathrm{KE}$, Harker LA. Left ventricular thrombi: In vivo detection by indium-111 platelet imaging and two-dimensional echocardiography. Am F Cardiol 1981; 47: 874-81.

6 Asinger RW, Mikell FL, Elsperger J, Hodges M. Incidence of left ventricular thrombosis after acute transmural myocardial infarction. $N$ Engl $f$ Med 1981; 305: 297-302.

7 The Norwegian Multicenter Study Group. Timololinduced reduction in mortality and reinfarction in patients surviving acute myocardial infarction. $N$ Engl f Med 1981; 304: 801-7.

8 Owren PA. Control of anticoagulant therapy. The use of new tests. Arch Intern Med 1963; 111: 248-58.

9 Segal JP, Stapleton JF, McClellan JR, Waller BF, Harvey WP. Idiopathic cardiomyopathy: clinical features, prognosis and therapy. Curr Probl Cardiol 1978; 3: 1-48.

10 Arita M, Ueno Y, Masuyama Y. Detection of intracardiac thrombi in a case of cardiomyopathy by twodimensional echocardiography. $\mathrm{Br}$ Heart $\mathcal{f}$ 1982; 47: 397-9. 